\title{
MODELLING AND ANALYSIS OF A NETWORK ORGANIZATION FOR COOPERATION OF MANUFACTURERS ON PRODUCTION CAPACITY
}

BARIŞ TAN

Received 28 November 2005; Accepted 2 January 2006

We present an analytical model to analyze the operation of a productive cooperation network where producers cooperate on production capacity. Producers have limited capacity and have access to subcontractors at a higher cost. A single-unit auction-based allocation mechanism is proposed to allocate an arriving order based on the producers' cost structures and their current loads to maximize the total profit. We show that when the costs are private information, producers are willing to cooperate in order to increase their expected profit. Furthermore, it is shown that there is an equilibrium where producers bid their actual costs. The cooperation can also generate extra profit to cover a part of its operating expenses with this allocation mechanism. A continuous-time Markov chain model is utilized to evaluate the performance of the allocation mechanism where producers submit their myopic best response bids. The cooperation case is also compared with the no-cooperation case and also with the centralized operation of producers.

Copyright (c) 2006 Barış Tan. This is an open access article distributed under the Creative Commons Attribution License, which permits unrestricted use, distribution, and reproduction in any medium, provided the original work is properly cited.

\section{Introduction}

1.1. Motivation. The purpose of this article is to analyze the operation of a productive cooperation network by using an analytical model. An association of autonomous business units operating jointly has been referred to as agile enterprise, joint venture, valueadding partnership, virtual corporation, and so forth, in the literature. We use the term network organization to refer to temporary cooperation of a number of independent companies to benefit from an opportunity in a market that neither of the firms can exploit on its own. For an extensive survey of the literature in network organizations, the reader is referred to the review of Van Alstyne [22].

The motivation of this study comes from the textile-apparel retail channel. A large buyer such as Wal-Mart, Federated, GAP, and so forth, deals with many small to medium size enterprizes (SMEs) that produce textile and apparel goods all over the world. The

Hindawi Publishing Corporation

Mathematical Problems in Engineering

Volume 2006, Article ID 85103, Pages 1-24

DOI 10.1155/MPE/2006/85103 
price is set by these buyers and the SMEs compete to get the order. In this setting, the profitability of an SME is dependent on controlling its costs. In order to be more competitive in global markets, a number of small to medium size companies can form a network organization and pool their support activities such as IT, human resources, and accounting. They can also benefit from joint purchasing of raw materials.

Italian textile mills operate in a similar way to achieve higher responsiveness to changes in fashion [12]. Kumar et al. also report a formation of a virtual enterprise in the Prato region (Italy) where a number of independent firms cooperate temporarily for each order [16]. EGS of Turkey was also a similar network organization that included a number of small to medium size textile and apparel exporters [8].

Similar network organizations have appeared in the recent years in other industries including agriculture [17], finance [5], and so forth. It is stated that collaboration with competitors by forming strategic alliances or joint ventures is an important strategy [9].

The network organization can also act as a marketing and sales division of its members to attract large orders from major customers. However, sharing a large order fairly and efficiently among the members is a major challenge to be addressed. Due to this challenge, cooperation on production capacity is limited. If a fair and efficient allocation can be guaranteed, a network organization introduces an opportunity that neither of the firms can exploit on its own.

1.2. A productive cooperation network. We consider a market with a number of independent small to medium size producers and a single large buyer who sets the price. We propose a network organization to facilitate cooperation on production capacity among the members. By becoming a member of this organization, producers act as a single entity to attract large size orders. However, members do not have any obligation to share their cost, capacity, and other critical information with other members.

When an order is received, members compete in an auction market to win the whole or a portion of the order by quoting their prices to produce a given number of items. The network organization awards the order to one of these producers to maximize the total profit. The difference between the price of the order and the payment to the producers yields an extra profit for the network organization. This accumulated extra profit is distributed equally among all the members of the network organization, after possibly keeping a portion to cover operational expenses of the cooperation.

In this setting, by utilizing an analytical model, we investigate the following questions: can independent manufacturers benefit if they cooperate on production capacity?, how should the network organization operate to award an arriving order?, and how should the network organization cover its operational expenses?

We consider a simple system with two producers and a buyer. Orders arrive randomly from the buyer following a Poisson process. The producers have limited capacity and the processing times are exponential random variables. They use subcontractors at a higher cost when their capacity is not sufficient. A threshold-type subcontracting policy is used to decide when to use subcontracting.

We propose a single-unit second-price sealed-bid (Vickrey) auction to award an auction. It is shown that when a second-price sealed-bid auction is used and the accumulated 


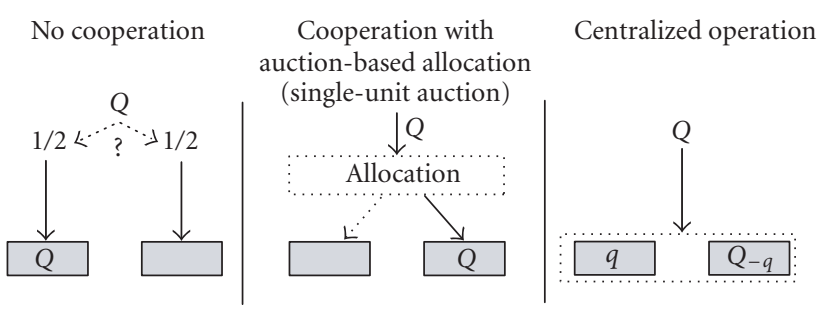

Figure 1.1. Comparison of different cases.

extra profit is shared with fixed side payments in each auction, producers will be willing to cooperate in order to increase their average profit. Furthermore, producers bid their actual production costs in a single-period model.

We also show that a portion of the accumulated profit can be kept to cover operational expenses of the cooperation. The maximum amount that can be kept to ensure feasibility while encouraging cooperation is determined.

We then use a continuous-time Markov chain model to evaluate the operation of this productive network in a dynamic setting. We compare three cases: no cooperation, cooperation with single-unit auction-based allocation, and the centralized operation where the producers operate as a single entity and produce an order jointly after it is split. Figure 1.1 depicts these three different cases for two producers.

Following the research questions stated above, the main contribution of this study is showing the benefit of a productive cooperation network by using an analytical model. We also suggest mechanisms for the operation of the network, namely, to allocate orders and cover its expenses. Specifically, we show that an auction-based allocation mechanism that utilizes a second-price (Vickrey) auction ensures fairness and efficiency of allocation and encourages cooperation on production capacity. We also show that state-space models can be utilized effectively to evaluate the performance of auction markets in a random and dynamic setting.

The organization of the remaining part of the paper is as follows. The related literature is reviewed in Section 1.3. The setting of the problem and the model are described in Section 2. In Section 3, an auction-based allocation mechanism is introduced and its properties are discussed in a single-period case. For the dynamic case, the continuoustime Markov chain models for independent operation of producers, cooperation of producers without splitting an order, and centralized operation are given in Section 4. Comparison of these cases are given in Section 5. Finally, conclusions are provided in Section 6.

1.3. Past work. In the recent years, a number of studies that investigate auctions in operations management applications appeared in the literature. We limit our discussion to the papers that discuss auctions in a supply chain setting especially for procurement and performance evaluation of auction-based systems. For a thorough review of auction theory, the reader is referred to the reviews in $[13,15]$.

Most of the studies that focus on reverse, or procurement, auctions consider a case with one buyer and multiple competing suppliers. The problem investigated in these 
studies is to design an auction that maximizes the buyer's utility by deciding the supplier that will be chosen.

Elmaghraby provides an overview of the contract competition and sourcing strategies that are studied in operations research and economics literature [6]. These studies examine various market structures and evaluate the performance of multiple and sole sourcing strategies within that market.

Dasgupta and Spulber present three mechanisms that are extensions of the standard fixed quantity auction to manage procurement auctions [4]. They consider dual or multiple sourcing in which two or more firms are simultaneously awarded the contract. In these cases, output is allocated across firms based on marginal costs.

Beil and Wein present an inverse-optimization-based auction mechanism to support a multiattribute request-for-quote (RFQ) process [1]. In addition to price, they also consider other attributes. By using an optimization-based algorithm, the buyer learns the cost functions of the suppliers from the bids that are collected in the first several rounds and then chooses a scoring rule to maximize his own utility at the last round. They assume that suppliers choose their minimum-cost, myopic-best-response bid to achieve any given score and they do not distort their bids in the earlier rounds. In a similar setting, Gallien and Wein present a multi-item procurement auction for a buyer in a capacity constrained environment where suppliers bid with myopic best response [7].

Huh and Roundy discuss the properties of reverse auctions when they are used for procurement [10]. In their setting, a buyer procures a single unit from one of many competing suppliers. They show that the buyer should prefer the second-price auction to the first-price auction.

Chen presents a model where a buyer procures an input from a number of potential suppliers [3]. A procurement strategy that maximizes the buyer's expected profits is analyzed. It is shown that the auction format affects the optimality of a quantity auction.

The number of studies that focus on supplier coalitions in a supply chain setting are limited. Jin and Wu investigate procurement auctions with supplier coalition with the idea of managed collusion to enhance bidder profitability with a mechanism design approach [11]. They propose a two-stage auction mechanism that allows suppliers to form coalitions with one another. A second-price descending seal-bid auction is used in the mechanisms. They identify requirements for a valid coalition. A detailed review of economic literature related to collusion in auctions and coalition formation can be found in this paper.

In a recent paper, Koppl and Monnet investigate the merger of two independent trading, clearing, and settlement organizations [14]. They show that when costs of settlements are private information, there is no incentive compatible and feasible mechanism that achieves an ex-post efficient merger between the two firms.

Another set of papers investigate the performance of systems that use auctions in mostly dynamic settings by using queueing models. For example, Vakrat and Seidmann investigate the effects of the bidders' arrival process on the online auctions by using a simple model [21]. Veeramani and Wang provide a model to evaluate the performance of auction-based distributed shop-floor control schemes [23]. They first analyze the associated queueing network approximately to identify control schemes and then use 
simulation to evaluate the performance of the system in detail. In a similar setting, Nandula and Dutta use Petri nets to evaluate the performance of a manufacturing system that uses auctions as a control strategy [18].

Nisan and Ronen consider algorithmic mechanism design problems in a distributed setting [19]. They apply auction-based allocation mechanisms in a task scheduling problem.

This study utilizes the second-price auction suggested by many papers in the literature including $[10,11]$ in a different setting. In our setting, from the buyer's perspective, the price is set and the order is given to the network organization and therefore there is no decision for the buyer. Auction is used internally to allocate the order. As opposed to many of the studies, we assume that producers do not have complete information about the others and they do not share their cost, capacity, and other critical information. Since, the members of the cooperation network are also competitors, the private information setting is critical. In this study, we did not derive the optimal bidding strategy in a dynamic setting. Instead we assume that producers submit their bids that maximize their expected profit in that period, that is, they submit their myopic best responses similar to $[1,7]$. As opposed to $[18,23]$, the performance evaluation model used in this study is based on a continuous-time Markov chain and yields exact results.

\section{Model}

Orders. We consider a system with two producers and a single customer. Orders of fixed size of $Q$ units each arrives randomly according to a Poisson distribution with rate $\lambda$. The price of each unit is $\xi$ and it is exogenously determined by the buyer. When the producers do not cooperate, each producer has an equal chance of receiving the order. Since the customer sets the price, this assumption states that the customer is indifferent between producers that can accept this price and meet the due date.

Bids and allocation. An auction mechanism is used to allocate an arriving order. Producer $i$ 's bid is denoted with $b_{i}$. When an order arrives and is allocated to producer $i$, the number of units producer $i$ gets from this allocation is denoted with $A_{i}$ and the amount paid to producer $i$ for the production of $A_{i}$ units is $\psi_{i}$. When the whole order is allocated to, say, producer $j$, then $A_{j}=Q$ and $A_{i}=0$ for $i \neq j$. However, in the centralized operation, the order is split among the producers, $A_{1}+A_{2}=Q, 0 \leq A_{i} \leq Q, i=1,2$.

Production modes. Producers follow a make-to-order production strategy. Accordingly they start production when an order arrives. Producer $i$ has two modes of production: it can produce in-house at a unit cost of $c_{i}$ and it can use a subcontractor at a unit cost of $o_{i}$. We assume that $c_{i}<o_{i}<\xi, i=1,2$.

The production time of a single product at producer $i$ is an exponentially distributed random variable with mean $1 / \mu_{i}, i=1,2$. We assume that there are many subcontractors available to produce at a cost of $o_{i}$ and effectively, the additional source has no capacity restriction.

We consider a threshold-type subcontracting policy. Accordingly, upon the arrival of allocated units from an order, if the number of parts at producer $i$ exceeds a threshold $Z_{i}$, the exceeding parts are sent to a subcontractor that delivers these parts before the 
due-date, while the remaining parts are produced in-house. We assume that the thresholds $Z_{i}$ are given exogenously. The thresholds can be chosen optimally based on the system parameters to minimize the total cost.

We use this suboptimal strategy to include an easy-to-implement subcontracting policy in our model. Although this strategy is the optimal subcontracting strategy for some systems under different assumptions $[2,20]$, the optimal strategy for the system studied in this paper is not derived.

Cost structure. The number of parts in producer $i$ at time $t$ is denoted with $N_{i}(t)$. The total cost of production for an arriving order depends on the producer's current load, $N_{i}(t)$, the regular and the subcontractor costs, and also on the subcontracting threshold.

The production function of producer $i$ that gives the total production cost of producing $A_{i}$ units when the order arrives is denoted with $f_{i}\left(A_{i}\right)$ and given as

$$
f_{i}\left(A_{i}\right)= \begin{cases}A_{i} c_{i}, & A_{i}+n_{i} \leq Z_{i} \\ \left(Z_{i}-n_{i}\right) c_{i}+\left(A_{i}+n_{i}-Z_{i}\right) o_{i}, & A_{i}+n_{i}>Z_{i}\end{cases}
$$

where $n_{i}=N_{i}(t)$.

This cost function shows that given the current load, a part of an arriving order up to the subcontracting threshold can be produced in-house at a per-unit cost of $c_{i}$. If this is not sufficient, remaining parts are produced by a subcontractor at a per-unit cost of $o_{i}$.

When a new order of size $Q$ has arrived, the cost of producing the whole order is denoted with $\theta_{i}=f_{i}(Q)$ for producer $i$. Note that since producers bid their total cost in a single-unit auction, the details of production modes and cost structure are used in the evaluation of the performance of the auction mechanism in a dynamic setting.

Information structure. We assume that producers do not have information about the other producers and they do not share their private capacity, subcontracting, and cost parameters with the other members of the cooperation.

The total costs $\theta_{1}$ and $\theta_{2}$ are private information of producers. Without any information, producer $i$ believes that $\theta_{j}$ is distributed according to the uniform distribution with support $[0, \bar{\theta}]$ and density $g(x)=1 / \bar{\theta}, 0 \leq x \leq \bar{\theta}$ for all $j \neq i$. We do not also consider the possibility of learning about other producers through interacting with them in a dynamic setting. Finally, producers are risk-neutral.

\section{An auction-based mechanism to allocate an order}

3.1. Auction mechanism and fixed payments. We propose using a second-price sealedbid auction to allocate a given order. In a second-price sealed-bid auction, or Vickrey auction, the lowest bidder gets the order and paid the second lowest bid to produce the order. Similarly, if there are ties, each winning bidder has an equal likelihood of being awarded the order.

Since the order has a fixed price, the cooperation makes an extra profit that is equal to the difference between the total revenue, $Q \xi$, and the payment to the lowest bidder. The extra profit accumulated in the long run is distributed equally among the producers, possibly after using a part of it for expenses. The motivation for equal sharing of extra profit 
comes from treating the cooperating producers equally as members of this cooperation to benefit from this extra profit.

When a new order is allocated, the amount the cooperation pays to each producer as a share of the accumulated extra profit is fixed and denoted with $C$. As $C$ increases, the cooperation becomes more attractive. However, in order to maintain feasibility in the long run, the total amount paid should not exceed the accumulated extra profit. Note that, with this approach, the network organization may have a deficit or a surplus at a given time and the feasibility is ensured in the long run. We assume that the network organization has sufficient funds to accommodate deficits temporarily. The extra amount kept by the network organization can also be interpreted as the premium paid to guarantee payment of the extra profit in the case of a temporary deficit. We determine the maximum amount that can be kept to cover expenses of the network organization in Proposition 3.3.

3.2. Analysis of the auction mechanism. In a second-price sealed-bid auction, it is shown that the dominant strategy is to bid the actual cost [15]. We next investigate the behavior of producers when they are offered such a cooperation agreement with a secondorder auction and a side payment in a single period.

Let $\Pi_{i}\left(b_{1}, b_{2}\right)$ be the total profit the producer $i$ makes when the producers bid $b_{1}$ and $b_{2}$. Let us consider producer 1 . When producer 1's bid is lower than producer 2's bid, the order is awarded to producer 1 and it is paid the second lowest bid which is producer 2's bid, $b_{2}$. Then the profit from this order is the difference between the payment and its cost, that is, $b_{2}-\theta_{1}$. With the fixed side payment, the total profit will be $C+b_{2}-\theta_{1}$. When $b_{1}=b_{2}$, producer 1 has a $1 / 2$ chance of receiving the order. Accordingly, its profit is $C+(1 / 2)\left(b_{2}-\theta_{1}\right)$. Finally, when producer 1's bid is greater than producer 2's bid, the order is awarded to producer 2 and producer 1 only gets the side payment of $C$. Then, $\Pi_{1}\left(b_{1}, b_{2}\right)$ is written as

$$
\Pi_{1}\left(b_{1}, b_{2}\right)= \begin{cases}C+b_{2}-\theta_{1} & \text { if } b_{1}<b_{2} \\ C+\frac{1}{2}\left(b_{2}-\theta_{1}\right) & \text { if } b_{1}=b_{2} \\ C & \text { if } b_{1}>b_{2}\end{cases}
$$

Similarly, $\Pi_{2}\left(b_{1}, b_{2}\right)$ is given as

$$
\Pi_{2}\left(b_{1}, b_{2}\right)= \begin{cases}C+b_{1}-\theta_{2} & \text { if } b_{2}<b_{1}, \\ C+\frac{1}{2}\left(b_{1}-\theta_{2}\right) & \text { if } b_{2}=b_{1} \\ C & \text { if } b_{2}>b_{1}\end{cases}
$$

3.2.1. Producers bid their actual production costs. With this structure, bidding a value other than its actual production cost does not improve the producer's payoff. Therefore the dominant strategy for a producer is to reveal the truth and bid its actual cost.

We next show that there is an equilibrium where producers bid their actual costs to maximize their single-period expected return by using their estimates of other bidders' costs. 
Proposition 3.1. For two producers in a single-period setting, when a second-price sealedbid auction is used to allocate the order and the extra profit is distributed equally, there is a Bayesian-Nash equilibrium such that both producers reveal the truth, that is, the producers bid their costs and

$$
E\left[\Pi_{i}\left(\theta \mid \theta_{i}\right)\right] \geq E\left[\Pi_{i}\left(\theta \mid \theta_{i}^{*}\right)\right] \quad \forall \theta_{i}^{*}, i=1,2,
$$

where $\theta=\left(\theta_{1}, \theta_{2}\right)$.

The proof of the proposition is not given here and follows the standard results in the literature [15].

3.2.2. Producers cooperate if the side payment is large enough. Note that the above result is independent of the extra payment $C$. We next investigate whether producers will be willing to participate in this cooperation with the limited information they have.

Proposition 3.2. For two producers, this mechanism is individually rational, that is, the expected profit for each player from cooperation is at least as high as the profit they make without cooperating when $C \geq(Q \xi-\bar{\theta}) / 2$.

Proof. When the producers do not cooperate, producer $i$ has a chance of $1 / 2$ getting the order. Considering producer 1 , the expected profit when there is no cooperation is simply $E\left[\tilde{\Pi}_{1}\right]=(1 / 2)\left(Q \xi-\theta_{1}\right)$. For the cooperation case, the expected profit when producer 1 bids its actual cost is given as

$$
E\left[\Pi_{1}\left(\theta \mid \theta_{1}\right)\right]=\int_{\theta_{1}}^{\bar{\theta}}\left(C+\theta_{2}-\theta_{1}\right) g\left(\theta_{2}\right) d \theta_{2}+\int_{0}^{\theta_{1}} C g\left(\theta_{2}\right) d \theta_{2}
$$

Then the difference between the profit with cooperation and without cooperation is evaluated as

$$
E\left[\Pi_{1}\left(\theta \mid \theta_{1}\right)\right]-E\left[\widetilde{\Pi}_{1}\right]=\frac{1}{2 \bar{\theta}}\left(2 C \bar{\theta}+\left(\bar{\theta}-\theta_{1}\right)^{2}\right)-\frac{1}{2}\left(Q \xi-\theta_{1}\right) .
$$

The left-hand side of the above equation has its minimum at $\theta_{1}=\bar{\theta}$. For $\theta_{1}=\bar{\theta}$, the above expression is always greater than or equal to zero if

$$
C \geq \frac{Q \xi-\bar{\theta}}{2}
$$

When this condition holds, individually rationality is satisfied for all $0 \leq \theta_{1} \leq \bar{\theta}$. The case for producer 2 is symmetric and therefore the mechanism is individually rational for $C \geq(Q \xi-\bar{\theta}) / 2$. 
The above result shows that when such a cooperation is possible and a certain amount of extra profit is promised to be distributed to its members, risk-neutral producers would be willing to participate to maximize their expected profit based on their belief of the other producers' costs.

3.2.3. Side payment should not be too large. We now analyze the mechanism from the network organization perspective. Obviously, as the side payment increases, the cooperation will be more attractive. However, the total payment to producers should not exceed the total accumulated profit to ensure that the network is self-sufficient.

The following result gives a condition for the extra payment $C$ in order to ensure that the network organization is self-sufficient, that is, the payments to producers are covered from the generated revenues. This condition also determines the maximum amount that can be kept from the extra profit to pay for operational expenses of the cooperation.

Proposition 3.3. For two producers, when $C \leq Q \xi / 2-\bar{\theta} / 3$, the expected total payment to producers is less than or equal to the total revenue, that is, the network organization is feasible.

Proof. The expected payment to producer 1 is determined from (3.1) as

$$
E\left[\psi_{1}\right]=C+\frac{1}{\bar{\theta}^{2}} \int_{0}^{\theta_{1}} \int_{\theta_{1}}^{\bar{\theta}} \theta_{2} d \theta_{2} d \theta_{1}=C+\frac{\bar{\theta}}{3} .
$$

Since the expected payment to producer 2 is the same, the network organization's expected total payment is $2(C+\bar{\theta} / 3)$. Since these payments are made from the total revenue, $Q \xi \geq 2(C+\bar{\theta} / 3)$ which yields

$$
C \leq \frac{Q \xi}{2}-\frac{\bar{\theta}}{3}
$$

Note that this condition ensures that the total payments to the producers are covered from the total extra profit, that is, it ensures feasibility on the average. For a given auction, the total payment may exceed the total revenue. In a similar setting, when the total revenue is to be distributed between two producers, it is shown that there is no incentive compatible, feasible, and ex-post efficient mechanism with the property that total payments are equal to total revenue, that is, $\psi_{1}+\psi_{2}=Q \xi$ [14]. When the same mechanism is used for many auctions, the condition satisfies feasibility in the long run.

3.2.4. Network organization's share should be limited. By combining conditions (3.6) and (3.8), the maximum amount that the network organization can keep from the accumulated extra profit to cover its expenses can be determined.

Let $\widetilde{C}$ be the amount kept for the network organization. Then it follows directly from (3.6) and (3.8) that the maximum amount that can be kept to cover the expenses of the network organization is $\bar{\theta} / 3$. The fixed side payment to producers is then written as

$$
C=\frac{Q \xi}{2}-\frac{\widetilde{C}}{2}-\frac{\bar{\theta}}{3}, \quad 0 \leq \widetilde{C} \leq \frac{\bar{\theta}}{3}
$$


With this extra payment, the proposed single-unit second-price auction-based allocation mechanism encourages producers to cooperate and also covers the expenses of the network from the extra profit generated. For simplicity, we assume that the network organization distributes all the extra money and does not keep any portion for operating expenses, that is, $\widetilde{C}=0$.

We next analyze the operation of the mechanism in a dynamic setting with the details of production and costs.

\section{Productive cooperation network in a dynamic setting}

We now consider a dynamic setting where orders arrive randomly and are distributed between the producers. In this case, the current load of the producers affect their cost structure and therefore their bids for the next order. Then allocation of this new order changes the loads of the producers and therefore affects their cost structure for the next order.

In the dynamic setting, we do not take into account the strategic behavior of the bidders in the dynamic setting and we assume that producers submit their myopic bestresponse (MBR) bids. The MBR assumption states that a producer using MBR chooses its next bid to maximize her current profit, assuming no other suppliers change their bids. That is, producer acts as if the auction was ending after its bid [1]. The myopic best response assumption has been used in a variety of recent studies, for example, $[7,24]$, and sometimes referred to as "straightforward bidding."

As analyzed in the previous section, in addition to the profits producers make from the allocated orders, an extra profit is made. The accumulated extra profit is then distributed equally among the producers. The timing of the payment of this extra profit is not necessarily the same as the arrival of orders. It can be paid monthly, annually, and so forth. Since the system is analyzed in the steady-state, this does not affect the average results.

Under the MBR assumption, the performance of the allocation mechanism in a dynamic setting is evaluated by using a state-space model.

4.1. State space. We analyze this system in steady-state. The state of the system at time $t$ is $S(t)=\left(N_{1}(t), N_{2}(t)\right)$ with $|S(t)|=\left(Z_{1}+1\right) \times\left(Z_{2}+1\right)$. Due to the assumptions of exponential service time and Poisson arrivals, the process $\{S(t), t \geq 0\}$ is a continuous-time Markov process. Therefore, the steady-state probabilities can be determined easily.

The steady-state joint probability function is defined as

$$
p\left(n_{1}, n_{2}\right)=\lim _{t \rightarrow \infty} \operatorname{prob}\left[S(t)=\left(n_{1}, n_{2}\right)\right]
$$

Let $\mathbf{p}$ be a 1-by- $\left(Z_{1}+1\right) \times\left(Z_{2}+1\right)$ row vector of probabilities

$$
\mathbf{p}=\left[p(0,0), p(0,1), \ldots, p\left(0, Z_{2}\right), p(1,0), \ldots, p\left(Z_{1}, Z_{2}\right)\right]
$$


Let $R$ be the transition rate matrix of the process $\{S(t), t \geq 0\}$. Once $R$ is determined for different allocation mechanisms, the steady-state probabilities can be determined from

$$
\begin{gathered}
\mathbf{p} R=\mathbf{0} \\
\sum_{n_{1}=0}^{Z_{1}} \sum_{n_{2}=0}^{Z_{2}} p\left(n_{1}, n_{2}\right)=1 .
\end{gathered}
$$

The state-transitions are governed by the allocation mechanism that is used to allocate an arriving order. Once the allocation of the order is determined, the profit of producers, the extra profit, and other performance measures can be derived from the steady-state probabilities.

4.2. Performance measures. The average total profit producer $i$ gets per unit time in the long run $\pi_{i}^{*}$ is the sum of the profit from producing awarded orders $\pi_{i}$ and the side payment from the extra profit the cooperation generates $\underline{\pi}$. When all of the extra profit is allocated equally between the producers, $\pi_{i}^{*}=\pi_{i}+(1 / 2) \underline{\pi}$.

The fraction of the total number of units producer $i$ gets is denoted by $\eta_{i}$. The fraction of all the units allocated to producer $i$ in the long run can be determined from the steadystate probabilities as

$$
\eta_{i}=\frac{1}{Q} \sum_{n_{1}=0}^{Z_{1}} \sum_{n_{2}=0}^{Z_{2}} A_{i} p\left(n_{1}, n_{2}\right), \quad i=1,2
$$

where $A_{i}$ depends on $n_{1}$ and $n_{2}$.

We also calculate the average cost of producing an order to evaluate the efficiency of the industry as a whole. Comparing the total revenue and the total profit of the cooperation and individual producers yields the average cost per unit $\underline{\theta}$ given as

$$
\underline{\theta}=\frac{1}{Q} \sum_{n_{1}=0}^{Z_{1}} \sum_{n_{2}=0}^{Z_{2}}\left(f_{1}\left(A_{1}\right)+f_{2}\left(A_{2}\right)\right) p\left(n_{1}, n_{2}\right)=\xi-\frac{\pi+\pi_{1}+\pi_{2}}{Q \lambda}
$$

We next model independent operation of producers, cooperation of producers without splitting an order, and centralized operation. These cases are depicted in Figure 1.1.

4.3. No cooperation (Case I). First we investigate the independent operation of producers. The producers do not cooperate and the buyer places the order at one of the producers with equal probability.

Therefore when orders arrive randomly according to the Poisson distribution with rate $\lambda$, the arrival rate of orders to producer $i$ is $\lambda_{i}=\lambda / 2, i=1,2$.

The model for producer $i$ is an $M / M / 1 / Z_{i}$ queue with batch arrivals of size $Q$. The two systems are independent of each other and

$$
p\left(n_{1}, n_{2}\right)=p\left(n_{1}\right) p\left(n_{2}\right),
$$


where

$$
p\left(n_{i}\right)=\lim _{t \rightarrow \infty} \operatorname{prob}\left[N_{i}(t)=n_{i}\right]
$$

In each system, the state space includes the number of units in the system, that is, $0,1, \ldots, Z_{i}$. We describe the state-space model of this allocation mechanism for producer $i$ by determining the elements of the state transition rate matrix $R_{i}$.

There are two possible events, an arrival of a batch of size $Q$ and a service completion. When the state of the system is $k=n_{i}$,

(i) when an order arrives, the state changes to $j=\min \left(n_{i}+Q, Z_{i}\right)$ and $R_{i}(k, j)=\lambda_{i}$,

(ii) when the producer completes production, the system changes to $j=n_{i}-1$ for $n_{i}>0$ and $R_{i}(k, j)=\mu_{i}$. and $R_{i}(k, k)=-\sum_{k \neq j} R_{i}(k, j)$.

Solution of (4.3) with the obtained $R_{i}$ values yields the steady-state probabilities for the no-cooperation case. Then, the average profit producer $i$ makes per unit time is the difference between the revenues and the average costs:

$$
\pi_{i}^{*}=\lambda_{i}\left(\sum_{n_{i}=0}^{Z_{i}}\left(Q \xi-f_{i}(Q)\right) p\left(n_{i}\right)\right), \quad i=1,2 .
$$

In this case, the fraction of all the units producer $i$ gets is simply $\eta_{i}=1 / 2$.

4.4. Cooperation with single-unit auction-based allocation (Case II). We now examine the case where the producer who bids the lowest for the order gets the whole order of $Q$ units and is paid the second lowest bid. The ties are broken with equal probability.

4.4.1. State-space model. We describe the state-space model of this allocation mechanism by determining the elements of the state-transition rate matrix $R$.

Let $i=\left(n_{1}, n_{2}\right)$ be the current state of the system. There are three possible transitions from state $i$ : service completion at producer 1 , service completion at producer 2 , and arrival of an order of size $Q$.

When an order arrives, depending on the production costs of the producers that are also their bids, there are three possibilities.

(i) $f_{1}(Q)<f_{2}(Q)$. Producer 1 gets the order. The state of the system changes to $j_{1}=$ $\left(\min \left(Z_{1}, n_{1}+Q\right), n_{2}\right)$ and $R\left(i, j_{1}\right)=\lambda$.

(ii) $f_{1}(Q)>f_{2}(Q)$. Producer 2 gets the order. The state of the system changes to $j_{2}=$ $\left(n_{1}, \min \left(Z_{2}, n_{2}+Q\right)\right)$ and $R\left(i, j_{2}\right)=\lambda$.

(iii) $f_{2}(Q)=f_{2}(Q)$. Each producer gets the order with $1 / 2$ probability. The state of the system changes either to $j_{3}=\left(n_{1}, \min \left(Z_{2}, n_{2}+Q\right)\right)$ or to $j_{3}^{*}=\left(\min \left(Z_{1}, n_{1}+\right.\right.$ $\left.Q), n_{2}\right)$. For these cases, $R\left(i, j_{3}\right)=\lambda / 2$ and $R\left(i, j_{3}^{*}\right)=\lambda / 2$.

Service completion is only possible when the producer is not idle. When producer 1 finishes its operation, the system changes to $j_{4}=\left(n_{1}-1, n_{2}\right)$ and $R\left(i, j_{4}\right)=\mu_{1}$ for $n_{1}>0$. Similarly, When producer 2 finishes its operation, the system changes to $j_{5}=\left(n_{1}, n_{2}-1\right)$ and $R\left(i, j_{5}\right)=\mu_{2}$ for $n_{2}>0$. 
Combining these transitions, the elements of $R$ can be summarized for $i \neq j$ as

$$
R(i, j)= \begin{cases}\lambda \quad & \begin{array}{l}
f_{1}(Q)>f_{2}(Q), j=\left(n_{1}, \min \left(Z_{2}, n_{2}+Q\right)\right) \text { or } \\
f_{1}(Q)<f_{2}(Q), j=\left(\min \left(Z_{1}, n_{1}+Q\right), n_{2}\right),
\end{array} \\
\frac{\lambda}{2} & \text { if } f_{1}(Q)=f_{2}(Q),\left\{\begin{array}{l}
j=\left(n_{1}, \min \left(Z_{2}, n_{2}+Q\right)\right) \text { or } \\
j=\left(\min \left(Z_{1}, n_{1}+Q\right), n_{2}\right),
\end{array}\right. \\
\mu_{1} \quad \text { if } n_{1}>0, j=\left(n_{1}-1, n_{2}\right), \\
\mu_{2} \quad \text { if } n_{2}>0, j=\left(n_{1}, n_{2}-1\right) .\end{cases}
$$

Finally, $R(i, i)=-\sum_{i \neq j} R(i, j)$

Solution of (4.3) yields the steady-state probabilities for the case of allocating the whole orders without a split by using a second-price auction.

4.4.2. Allocation rates. The fraction of all the units producer 1 gets can be calculated from the steady-state probabilities as

$$
\eta_{1}=\sum_{f_{1}(Q)<f_{2}(Q)} p\left(n_{1}, n_{2}\right)+\frac{1}{2} \sum_{f_{1}(Q)=f_{2}(Q)} p\left(n_{1}, n_{2}\right) .
$$

Similarly, the fraction of all the units producer 2 gets is

$$
\eta_{2}=\sum_{f_{1}(Q)>f_{2}(Q)} p\left(n_{1}, n_{2}\right)+\frac{1}{2} \sum_{f_{1}(Q)=f_{2}(Q)} p\left(n_{1}, n_{2}\right)
$$

or equivalently, $\eta_{2}=1-\eta_{1}$. Then the average number of units producer $i$ gets per unit time is $\lambda Q \eta_{i}$.

4.4.3. Profits. The profit producer 1 makes from each arriving order is the difference between the price paid to producer 1 which is the bid of producer 2 and the cost of producer 1 . Then the average profit per unit time is

$$
\pi_{1}=\lambda \sum_{f_{1}(Q)<f_{2}(Q)}\left[f_{2}(Q)-f_{1}(Q)\right] p\left(n_{1}, n_{2}\right) .
$$

Similarly, the profit producer 2 makes from each order is the difference between the price paid to producer 2 which is the bid of producer 1 and the cost of producer 2 . Then the average profit per unit time is

$$
\pi_{2}=\lambda \sum_{f_{1}(Q)>f_{2}(Q)}\left[f_{1}(Q)-f_{2}(Q)\right] p\left(n_{1}, n_{2}\right) .
$$


The extra profit the cooperation makes from this order is the difference between the revenue from the order and the payment to the producer. Then the average rate at which the extra profit is generated is

$$
\underline{\pi}=\lambda Q \xi-\lambda \sum_{f_{1}(Q) \leq f_{2}(Q)} f_{2}(Q) p\left(n_{1}, n_{2}\right)-\lambda \sum_{f_{1}(Q)>f_{2}(Q)} f_{1}(Q) p\left(n_{1}, n_{2}\right) .
$$

Since this extra profit is shared equally between the two producers, the total profit producer $i$ makes in this mechanism is

$$
\pi_{i}^{*}=\pi_{i}+\frac{1}{2} \underline{\pi}
$$

4.5. Centralized operation (Case III). In the previous section, we examined the case where the whole order is allocated to one of the producers without splitting. However, splitting the order among the producers utilizes the total capacity of the producers better and reduces the total cost of producing the order. Since the total cost is reduced, the total profit increases.

As a benchmark case, the centralized operation of two producers is considered. In this case, we assume that two production units are owned and operated by the same company. Therefore, an arriving order is allocated between the producers in a such a way that the total cost of producing the order is minimized and $\sum_{i=1}^{N} A_{i}=Q$. In the centralized operation, the order is split between the two production sources in order to utilize the available capacity in the most efficient way.

4.5.1. State-space model for the centralized operation (Case III). The state-space model of this allocation mechanism is built again by determining the elements of the statetransition rate matrix $R$.

Let $i=\left(n_{1}, n_{2}\right)$ be the current state of the system. There are three possible transitions from state $i$, service completion at producer 1 , service completion at producer 2 , and arrival of an order of size $Q$.

When an order arrives, since the order is to be split, rather than the full production costs, unit production and subcontracting costs are relevant. We first determine the allocation of orders.

Considering the regular production costs, there are three cases, $\left.c_{1}<c_{2}, c_{1}\right\rangle c_{2}$, and $c_{1}=c_{2}$. We assume that whenever there will be a tie in costs, orders will be equally split. In the case of a tie, alternative allocation methods that are also based on the capacity can also be utilized to further improve the performance of the centralized case.

(1) $c_{1}<c_{2}$. In this case, if producer 1 can produce the whole order at $c_{1}$, that is, when $Z_{1}-n_{1} \geq Q$, the order is allocated to producer 1 . That is, $A_{1}=Q$ and $A_{2}=0$.

Otherwise, the allocation depends on the remaining regular capacity of producer 1 and the comparison of the subcontracting costs with the regular production cost of producer 2 .

(i) $c_{1}<c_{2}, Z_{1}-n_{1}<Q, Q-Z_{1}+n_{1} \leq Z_{2}-n_{2}$. In this case, after the regular production capacity of producer 1 is utilized, the remaining portion is allocated to producer 2. As a result, $A_{1}=Z_{1}-n_{1}$ and $A_{2}=Q-Z_{1}+n_{1}$. 
(ii) $c_{1}<c_{2}<o_{1}<o_{2}, Z_{1}-n_{1}<Q, Q-Z_{1}+n_{1}>Z_{2}-n_{2}$. In this case, after the regular production capacities of producers 1 and 2 are exhausted, the remaining portion is allocated to producer 1 which has a cheaper subcontractor. As a result, $A_{1}=Q-Z_{2}+n_{2}$ and $A_{2}=Z_{2}-n_{2}$.

(iii) $c_{1}<c_{2}<o_{2}<o_{1}, Z_{1}-n_{1}<Q, Q-Z_{1}+n_{1}>Z_{2}-n_{2}$. In this case, after the regular production capacities of producers 1 and 2 are exhausted, the remaining portion is allocated to producer 2 which has a cheaper subcontractor. As a result, $A_{1}=Z_{1}-n_{1}$ and $A_{2}=Q-Z_{1}-n_{1}$.

(iv) $c_{1}<o_{1} \leq c_{2}$. In this case, the whole order can be produced by producer 1 , that is, $A_{1}=Q$ and $A_{2}=0$.

(2) $c_{1}>c_{2}$. This is the symmetric case of the allocations given above. Namely, when $Z_{2}-n_{2} \geq Q$, the order is allocated to producer 2: $A_{1}=0$ and $A_{2}=Q$. Otherwise,

(i) $c_{2}<c_{1}, Z_{2}-n_{2}<Q, Q-Z_{2}+n_{2} \leq Z_{1}-n_{1}: A_{1}=Q-Z_{2}+n_{2}$ and $A_{2}=Z_{2}-$ $n_{2}$.

(ii) $c_{2}<c_{1}<o_{2}<o_{1}, Z_{2}-n_{2}<Q, Q-Z_{2}+n_{2}>Z_{1}-n_{1}: A_{1}=Z_{1}-n_{1}$ and $A_{2}=$ $Q-Z_{1}+n_{1}$.

(iii) $c_{2}<c_{1}<o_{1}<o_{2}, Z_{2}-n_{2}<Q, Q-Z_{2}+n_{2}>Z_{1}-n_{1}: A_{1}=Q-Z_{2}-n_{2}$ and $A_{2}=Z_{2}-n_{2}$.

(iv) $c_{2}<o_{2} \leq c_{1}: A_{1}=0$ and $A_{2}=Q$.

(3) $c_{1}=c_{2}$. When the regular production costs are the same and the order can be produced with only regular capacity, that is, $Z_{1}-n_{1}+Z_{2}-n_{2} \geq Q$, then we assume that the order is split between the two production facilities of the firm in order to balance the load. Then

(i) if $Z_{1}-n_{1} \geq Q / 2$ and $Z_{2}-n_{2} \geq Q / 2$, then $A_{1}=Q / 2$ and $A_{2}=Q / 2$;

(ii) if $Z_{1}-n_{1}<Q / 2$, then $A_{1}=Z_{1}-n_{1}$ and $A_{2}=Q-Z_{1}+n_{1}$;

(iii) if $Z_{2}-n_{2}<Q / 2$, then $A_{1}=Q-Z_{2}+n_{2}$ and $A_{2}=Z_{2}-n_{2}$.

If the regular production capacity is not sufficient, that is, $Z_{1}-n_{1}+Z_{2}-n_{2}<Q$, then a comparison of subcontracting costs yields the allocation.

(iv) $o_{1}<o_{2}$ and $Z_{1}-n_{1}+Z_{2}-n_{2}<Q$ : $A_{1}=Q-Z_{2}+n_{2}$ and $A_{2}=Z_{2}-n_{2}$.

(v) $o_{1}>o_{2}$ and $Z_{1}-n_{1}+Z_{2}-n_{2}<Q$ : $A_{1}=Z_{1}-n_{1}$ and $A_{2}=Q-Z_{1}+n_{1}$.

(vi) $o_{1}=o_{2}$ and $Z_{1}-n_{1}+Z_{2}-n_{2}<Q: A_{1}=(1 / 2)\left(Q-Z_{2}+n_{2}+Z_{1}-n_{1}\right)$ and $A_{2}=(1 / 2)\left(Q+Z_{2}-n_{2}-Z_{1}+n_{1}\right)$.

When an order arrives, the state of the system after allocating the order among the producers according to the above rules can be determined easily. Let $j$ be the state of the system after the allocation. Considering the subcontracting thresholds, the new state after an arrival can be written as

$$
j=\left(\min \left(Z_{1}, n_{1}+A_{1}\right), \min \left(Z_{2}, n_{2}+A_{2}\right)\right)
$$

and $R(i, j)=\lambda$.

The other transitions are related to service completions which are identical to the ones given in Section 4.4.1. Service completion is only possible when the producer is not idle. When producer 1 finishes its operation, the system changes to $j_{4}=\left(n_{1}-1, n_{2}\right)$ and $R\left(i, j_{4}\right)=\mu_{1}$ for $n_{1}>0$. Similarly, When producer 2 finishes its operation, the system changes to $j_{5}=\left(n_{1}, n_{2}-1\right)$ and $R\left(i, j_{5}\right)=\mu_{2}$ for $n_{2}>0$. Finally, $R(i, i)=-\sum_{i \neq j} R(i, j)$. 
Solution of (4.3) with the obtained $R$ yields the steady-state probabilities for the centralized operation with splitting an arriving order among the producers to minimize the total cost of production.

4.5.2. Allocation rates and profits. Once $A_{1}$ and $A_{2}$ are determined for each state $\left(n_{1}, n_{2}\right)$ and the steady-state probabilities are found, (4.4) yields the average allocation rates $\eta_{1}$ and $\eta_{2}$.

In the centralized operation, there is no payment to producers and the total profit is the difference between the revenue and the total production costs. Therefore the rate at which the profit is generated per unit time is

$$
\underline{\pi}=\lambda\left(Q \xi-\sum_{n_{1}=0}^{Z_{1}} \sum_{n_{2}=0}^{Z_{2}}\left(f_{1}\left(A_{1}\right)+f_{2}\left(A_{2}\right)\right) p\left(n_{1}, n_{2}\right)\right) .
$$

Since this is a centralized operation and both producers are part of the same company, there is no issue of sharing this profit among the producers. However, in order to compare the result with other cases, we calculate the allocated total profit for each producer based on equal sharing of the extra profit. Then the total profit producer $i$ makes in this mechanism is

$$
\pi_{i}^{*}=\frac{1}{2} \underline{\pi}
$$

\section{Comparison of different allocation mechanisms in a dynamic setting}

In this section, we compare the centralized case, the single-unit second-price sealed bid auction, and the no-cooperation cases. We focus on producers' profits, profit increase obtained with respect to the no-cooperation case, the average cost of producing a unit, and allocation of orders. The average costs for Cases I, II, and III are denoted with $\underline{\theta}_{\mathrm{I}}, \underline{\theta}_{\mathrm{II}}$, and $\underline{\theta}_{\mathrm{III}}$, respectively.

5.1. Effect of the load of the system. Figures 5.1 and 5.2 show the effect of the arrival rate for a system with identical producers. In this case, since the producers are identical, the allocation rates are equal for all the cases, that is, $\eta_{1}=\eta_{2}=1 / 2$ for Cases I, II, and III.

Figure 5.1 quantifies the profit increase achieved by using the auction-based allocation mechanism and the centralized operation compared to the no-cooperation case for producer 1 . As the figure shows, the centralized operation of the order (Case III) yields the maximum profit when the arrival rate is low compared to the total capacity of the system. The single-unit auction-based allocation decreases the profit compared to the centralized case, however it still yields a higher profit compared to the no-cooperation case. As the load increases in the system, the difference between the auction-based allocation and the centralized operation decreases since mostly subcontractors are used in all cases.

In these examples, we used exogenously-given subcontracting thresholds for all cases. However, the subcontracting thresholds for the centralized case can be jointly optimized by taking the reduced arrival rate into account. This would increase the percentage improvement of the centralized case. 


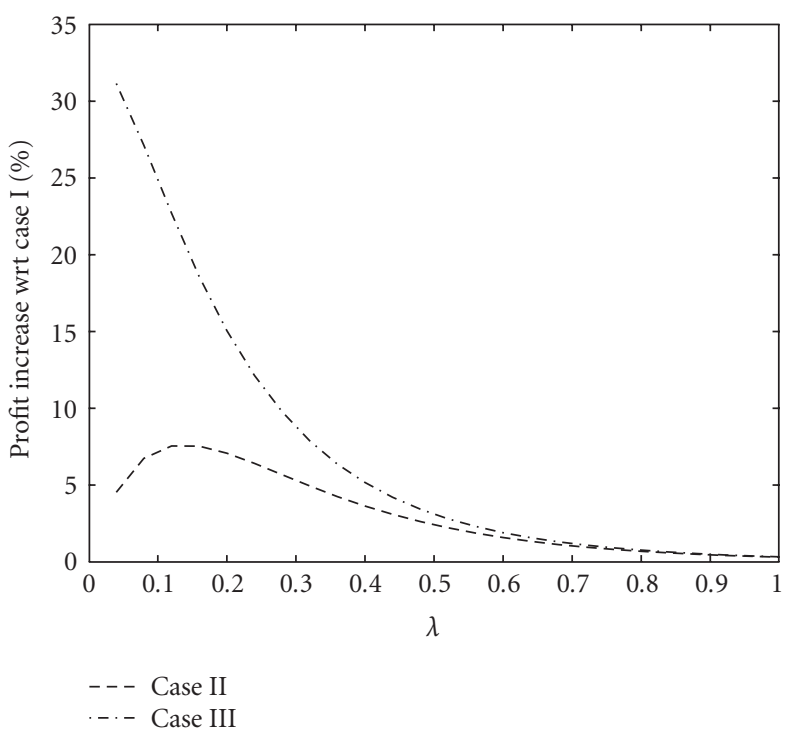

Figure 5.1. Effect of the arrival rate on the relative profit increase with respect to the random allocation for producer $1, \mu_{1}=1, \mu_{2}=1, Z_{1}=10, Z_{2}=10, Q=16, \xi=4, o_{1}=3, o_{2}=3, c_{1}=1, c_{2}=1$.

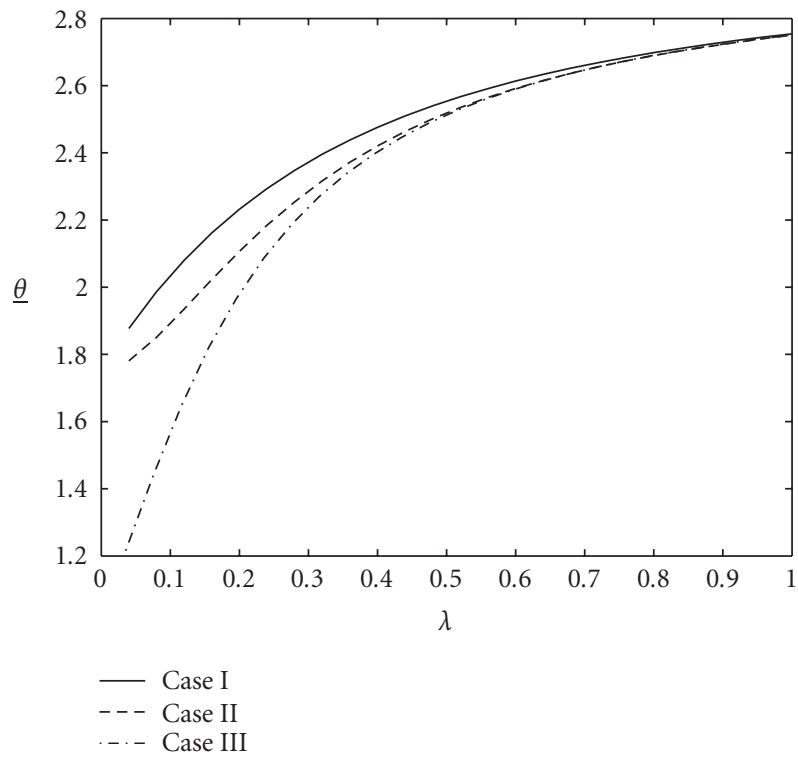

Figure 5.2. Effect of the arrival rate on the average production cost per unit of an arriving order, $\mu_{1}=1, \mu_{2}=1, Z_{1}=10, Z_{2}=10, Q=16, \xi=4, o_{1}=3, o_{2}=3, c_{1}=1, c_{2}=1$. 
In the no-cooperation case, $\lambda_{1}=\lambda_{2}=\lambda / 2$. When the load is very low compared to the total capacity, the producers are mainly idle. However, due to random arrival of orders, they still use subcontractors occasionally when they operate independently. In this case, centralized operation increases their profit by as much as $30 \%$, while the cooperation based on a single-unit auction increases their profit by as much as $8 \%$. As the load increases, subcontractors are used extensively, and the benefit of cooperation decreases. In between, producers use subcontractors occasionally and they remain idle at other times. The cooperation utilizes its capacity better in this case and yields higher relative profit increase compared to the very low and very high arrival rate cases. This explains the unimodal shape of the percentage increase of the cooperation case with respect to the no-cooperation case exhibited in Figure 5.1.

Figure 5.2 shows the average production cost of a unit in these different cases. The centralized case yields the lowest cost of production. Network organization allows the best utilization of its resources to achieve the possible lowest cost of production.

In order to derive insights, let us consider the case for identical producers. When an order arrives randomly, the cost of production is either $f_{1}(Q)$ or $f_{2}(Q)$. However, a singleunit auction is used, it is produced at $\min \left\{f_{1}(Q), f_{2}(Q)\right\}$. Since $\min \left\{f_{1}(Q), f_{2}(Q)\right\} \leq$ $f_{1}(Q)$ and $\min \left\{f_{1}(Q), f_{2}(Q)\right\} \leq f_{2}(Q)$, and if the steady-state distributions for both cases are assumed to be the same for identical producers, the average cost of production in the no-cooperation case is greater than the cost in the cooperation case.

As Figure 5.2 shows, the average unit cost of production that is obtained by using an auction-based allocation mechanism that is greater than the cost obtained in the centralized operation.

Let us again consider the case for identical producers. By using (4.5), (4.12), (4.13), and (4.14), The average unit cost for Case II can be written as

$$
\underline{\theta}_{\mathrm{II}}=\frac{1}{Q}\left(\sum_{f_{1}(Q) \leq f_{2}(Q)} f_{1}(Q) p\left(n_{1}, n_{2}\right)+\sum_{f_{1}(Q)>f_{2}(Q)} f_{2}(Q) p\left(n_{1}, n_{2}\right)\right)
$$

When an order is split, it is allocated among the producers in such a way that the total cost of production is minimized. That is, $A_{1}$ and $A_{2}$ are chosen such that $f_{1}\left(A_{1}\right)+f_{2}\left(A_{2}\right) \leq$ $f_{1}\left(x_{1}\right)+f_{2}\left(x_{2}\right)$ for all $\left\{x_{1}, x_{2}: x_{1}+x_{2}=Q, x_{1} \geq 0, x_{2} \geq 0\right\}$. Consequently, since $f_{1}\left(A_{1}\right)+$ $f_{2}\left(A_{2}\right) \leq f_{1}(Q)$ and $f_{1}\left(A_{1}\right)+f_{2}\left(A_{2}\right) \leq f_{2}(Q)$,

$$
\underline{\theta}_{\mathrm{II}} \geq \frac{1}{Q}\left(\sum_{f_{1}(Q) \leq f_{2}(Q)}\left(f_{1}\left(A_{1}\right)+f_{2}\left(A_{2}\right)\right) p\left(n_{1}, n_{2}\right)+\sum_{f_{1}(Q)>f_{2}(Q)}\left(f_{1}\left(A_{1}\right)+f_{2}\left(A_{2}\right)\right) p\left(n_{1}, n_{2}\right)\right) .
$$

Rearranging the above terms yields

$$
\underline{\theta}_{\mathrm{II}} \geq \frac{1}{Q} \sum_{n_{1}=0}^{Z_{1}} \sum_{n_{2}=0}^{Z_{2}}\left(f_{1}\left(A_{1}\right)+f_{2}\left(A_{2}\right)\right) p\left(n_{1}, n_{2}\right)
$$




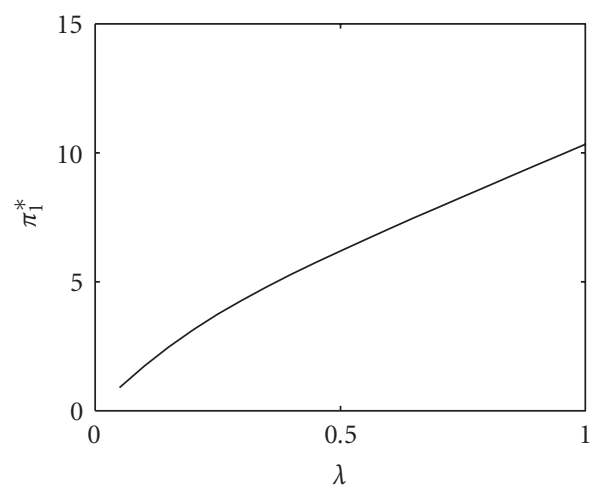

(a)

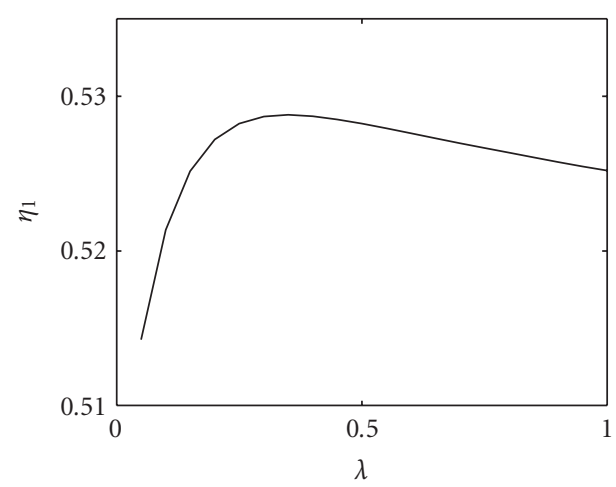

(c)

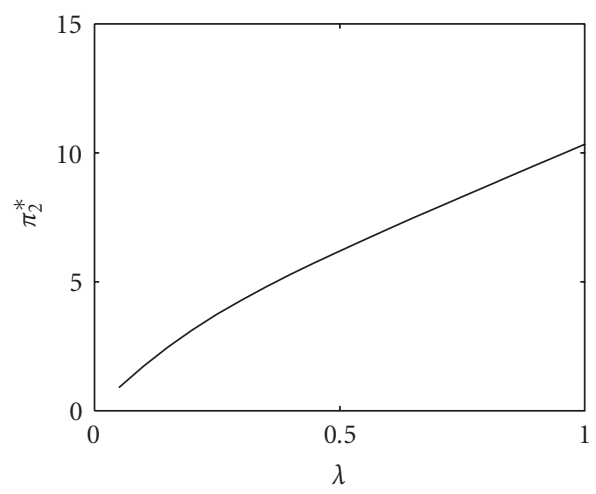

(b)

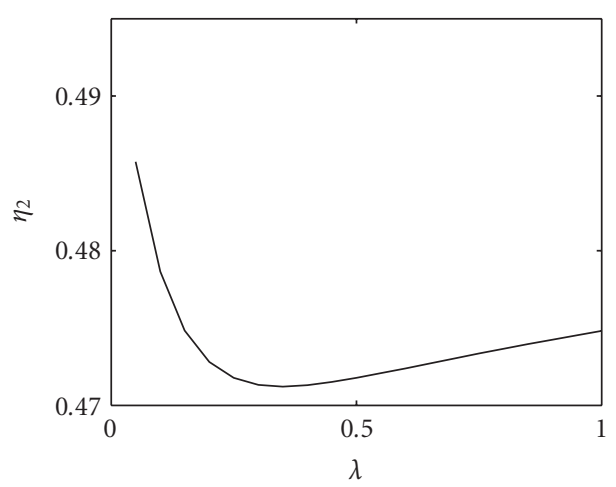

(d)

Figure 5.3. Effect of the arrival rate on the allocation of profits and orders, $\mu_{1}=1.2, \mu_{2}=1, Z_{1}=10$, $Z_{2}=10, Q=16, \xi=4, o_{1}=3, o_{2}=3, c_{1}=1, c_{2}=1$.

If we assume that the steady-state distribution $p\left(n_{1}, n_{2}\right)$ stays the same in both cases for identical producers, the right-hand side of the above equation is the average unit cost obtained by centralized operation, $\underline{\theta}_{\text {III }}$. Therefore $\underline{\theta}_{\text {II }} \geq \underline{\theta}_{\text {III }}$.

When the production capacities are different while all the other parameters are the same, the effect of arrival rate on the allocation of profits and orders is more complicated. Figure 5.3 shows the effects of arrival rate for a system with different production rates. Since producer 1 has higher capacity, its load when an order arrives is lower on the average compared to the other producer. As a result, it bids lower price and gets a higher share of the orders.

Figure 5.4 shows the percentage increase in the total profit with respect to the nocooperation case with $\lambda_{1}=\lambda_{2}=\lambda / 2$ for four different systems with differences in production capacity, regular production cost, subcontracting cost, and subcontracting thresholds, respectively. As expected, the centralized case yields higher profits compared to the 


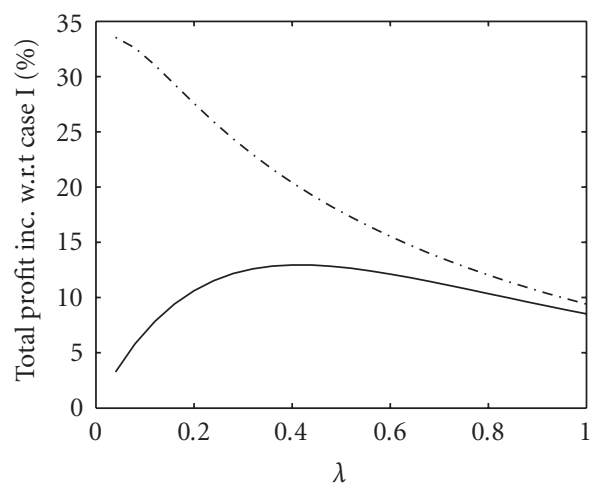

- Case II

- Case III

(a)

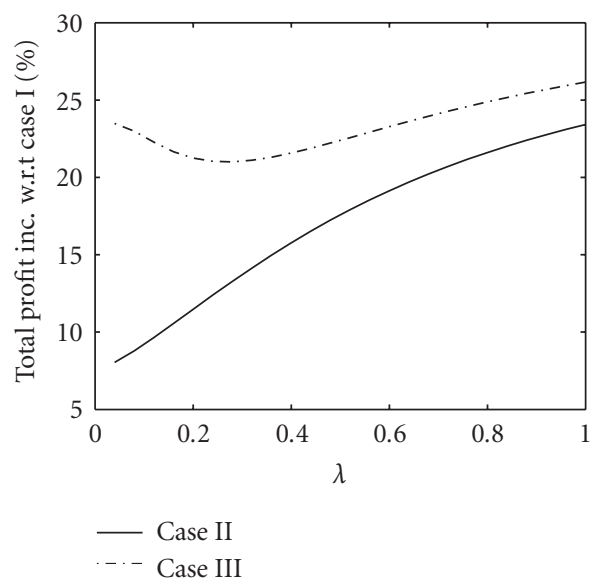

(c)

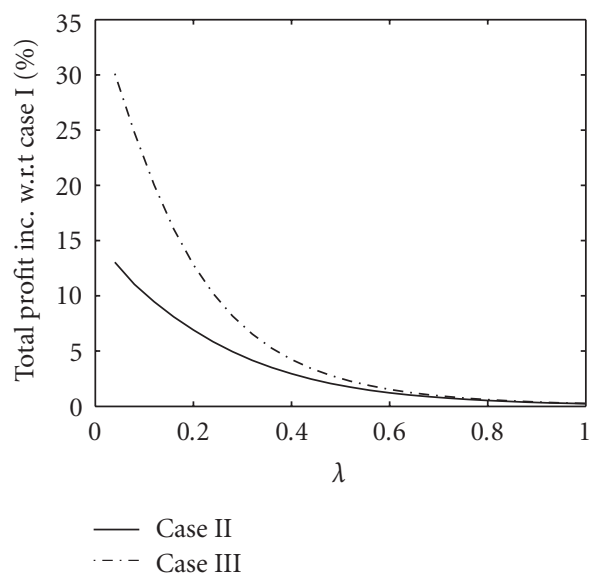

(b)

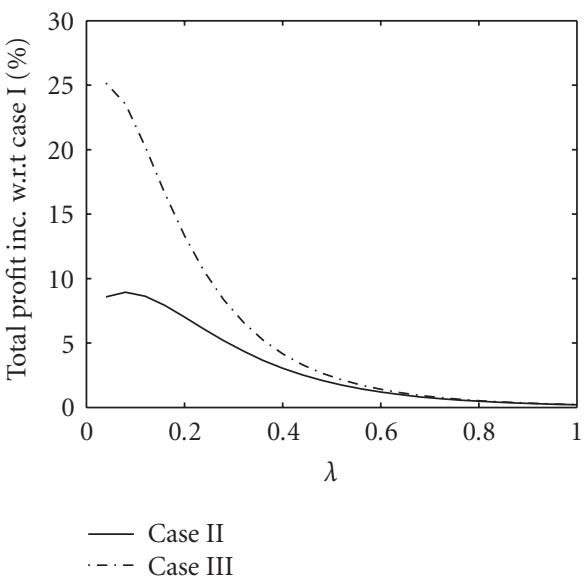

(d)

Figure 5.4. Increase in the total profit with respect to the no-cooperation case $Q=16, \xi=4$. (a) $\mu_{1}=5, \mu_{2}=1, Z_{1}=10, Z_{2}=10, o_{1}=3, o_{2}=3, c_{1}=1, c_{2}=1$. (b) $\mu_{1}=1, \mu_{2}=1, Z_{1}=10, Z_{2}=10$, $o_{1}=3, o_{2}=3, c_{1}=2, c_{2}=1$. (c) $\mu_{1}=1, \mu_{2}=1, Z_{1}=10, Z_{2}=10, o_{1}=2, o_{2}=3, c_{1}=1, c_{2}=1$. (d) $\mu_{1}=1, \mu_{2}=1, Z_{1}=13, Z_{2}=10, o_{1}=3, o_{2}=3, c_{1}=1, c_{2}=1$.

other cases. However, as the order rate increases, the performance of the auction-based allocation mechanism approaches the performance of the centralized case.

5.2. Effect of production capacity. Now, we investigate the effect of differences in producers' capacities on the allocation of orders and profits.

Figure 5.5 shows the fraction of the total units allocated to producer 1 and also the allocated profit of producer 1 for different values of production capacity. As expected, 


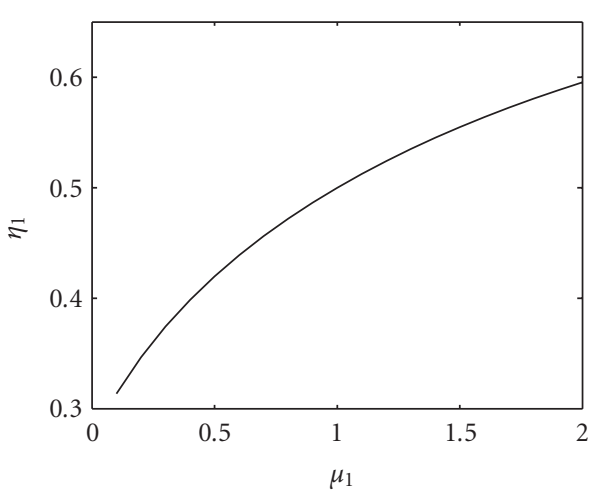

(a)

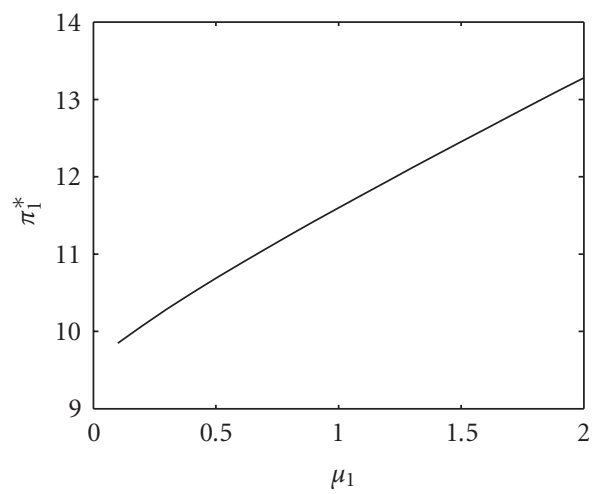

(b)

Figure 5.5. Effect of the production capacity on the allocation of orders and on producer 1's average profit, $\mu_{2}=1, \lambda=1.2, Z_{1}=10, Z_{2}=10, Q=16, \xi=4, o_{1}=3, o_{2}=3, c_{1}=1, c_{2}=1$.

increasing relative capacity compared to the other producer yields a higher allocation to producer 1.

Now, we summarize the results of our observations that validate our intuition. When the producers are identical, they increase their average profit compared to the nocooperation case by cooperating on production capacity. When the producers are identical, splitting the order yields a higher profit compared to the case where the order is allocated to one of the producers. Finally, the cooperation is effective when the producers' capacities are not heavily utilized.

\section{Conclusions}

In this paper, we discussed the cooperation of producers on production capacity. We propose an auction-based allocation mechanism to allocate orders and profits. It is shown that cooperation of producers is beneficial for members of the network organization and producers will be willing to cooperate even if a portion of the generated profit is kept to cover operational expenses of the cooperation.

A state-space model is built to analyze these auction-based allocation mechanisms in a dynamic setting. Especially when the members have similar characteristics and they cannot utilize their capacity at high levels, cooperation on production capacity increases their profit substantially compared to independent operation. This benefit comes from using regular capacity of the members more efficiently. In the noncooperative case, a producer may be forced to use a subcontractor at a higher cost while another producer has available regular capacity. Although an arriving order is now produced by another company, the same producer benefits from receiving additional production from other members when its regular capacity is underutilized.

We used a simple queueing model to study an interesting cooperation issue in a production setting with only two producers. The results can be extended to systems with 
more than two producers. Since the method is based on state space generation, the number of states and the number of computations to determine the performance measures increase rapidly. The computational complexity to determine the performance measures for $N$ producers is in the order of $\prod_{i=1}^{N}\left(Z_{i}+1\right)^{2}$. Since there are efficient algorithms to analyze large systems, the same method can be employed. Alternatively, the same technique can be embedded in a simulation study and the performance measures can be determined approximately.

In the model that we discuss, the customer is the leader and sets the price. Continuing the above example from the textile-apparel industry, for example, when GAP deals with a number of SMEs, it sets the price and if the price is not met, it can procure from another company globally. Therefore cooperation of its possible suppliers does not affect the customer negatively. On the contrary, the customer benefits from this situation by dealing only with a single supplier which is the joint venture of multiple independent producers that has great flexibility and speed.

The single-unit auction-based allocation mechanism can be extended to multiunit auctions where an arriving order is split among producers based on the bid vectors that submit. In a multiunit auction, allocation of orders and profits are based on in-house and subcontracting production costs, subcontracting threshold, and the current loads of producers. Therefore investigating this case for the private information case requires different assumptions on producers' estimates of the others' private parameters. Instead of using a single probability distribution for the estimate of total cost of producing an order for a single-unit auction, one needs different distributional assumptions for in-house and subcontracting costs and also for the number of units that can be produced in-house when a multiunit auction is used. In the multiunit auction case, there might be additional transportation costs due to sending an order to multiple locations.

Similarly, we model the decision of a producer only at a given time and assume that they act with their myopic-best response without taking long-term allocation of the generated extra profit similar to a number of studies in the literature. A more formal approach might use a dynamic programing methodology to see whether this is the case. However, since the information about the other members of the cooperation is not known, the producer's decision is more likely to depend on the current information.

For example, when a producer has limited regular capacity left, it may decide to bid a higher cost compared to its actual cost. As a result, the other producers may get the order and it will have a higher regular capacity and higher profit for the next order. However, in the case of no information sharing, this action does not guarantee higher profits. For example, producer 2 may have a much larger capacity. In this case, it finishes the order that is rejected by producer 1 and bids a competitive price for the next order. Examining the existence of an equilibrium where producers bid their costs equally in a dynamic setting is also left for future research.

\section{Acknowledgment}

This work is partially supported by the Turkish Academy of Sciences TUBA-GEBIP Program. 


\section{References}

[1] D. R. Beil and L. M. Wein, An inverse-optimization-based auction mechanism to support a multiattribute RFQ process, Management Science 49 (2003), no. 11, 1529-1545.

[2] J. R. Bradley, Optimal control of a dual service rate $M / M / 1$ production-inventory model, European Journal of Operational Research 161 (2005), no. 3, 812-837.

[3] F. Chen, Auctioning supply contracts, Working paper, Columbia University, New York, 2001.

[4] S. Dasgupta and D. F. Spulber, Managing procurement auctions, Information Economics and Policy 4 (1990), no. 1, 5-29.

[5] R. G. Eccles and D. B. Crane, Managing through networks in investment banking, California Management Review 30 (1987), no. 1, 176-195.

[6] W. Elmaghraby, Supply contract competition and sourcing policies, Manufacturing \& Service Operations Management 2 (2000), no. 4, 350-371.

[7] J. Gallien and L. M. Wein, A smart market for industrial procurement with capacity constraints, Management Science 51 (2005), no. 1, 76-91.

[8] P. Ghemawat and C. Fritz Foley, Cooperating to compete: egs of Turkey, Tech. Rep. 9-799-024, Harvard Business School Case, Massachusetts, 1998.

[9] G. Hamel, Y. L. Doz, and C. K. Prahalad, Collaborate with your competitors-and win, Harvard Business Review 67 (1989), no. 1, 133-139.

[10] W. T. Huh and R. O. Roundy, Using auctions for procurement, Tech. Rep. 1355, School of Operations Research and Industrial Engineering, Cornell University, New York, 2002.

[11] M. Jin and D. Wu, Procurement auction with supplier coalition: validity requirements and mechanism design, 2003, http://www.lehigh.edu/ sdw1/jin2.pdf.

[12] R. Johnston and P. R. Lawrence, Beyond vertical integration - the rise of the value-adding partnership, Harvard Business Review 66 (1988), no. 4, 94-101.

[13] P. Klemperer, Auction theory: a guide to the literature, Journal of Economic Surveys 13 (1999), no. 3, 227-286.

[14] T. V. Köppl and C. Monnet, Guess what: it's the settlements, Working paper 375, European Central Bank' Directorate General Research, 2004.

[15] V. Krishna, Auction Theory, Academic Press, California, 2002.

[16] K. Kumar, H. G. van Dissel, and P. Bielle, The merchant of Prato-revisited: towards a third rationality of information systems, Management Information Systems Quarterly (1996), 1-37.

[17] I. Mezgár, G. Kovács, and P. Paganelli, Co-operative production planning for small- and mediumsized enterprises, International Journal of Production Economics 64 (2000), no. 1-3, 37-48.

[18] M. Nandula and S. P. Dutta, Performance evaluation of an auction-based manufacturing system using coloured petri nets, International Journal of Production Research 38 (2000), no. 10, 21552171.

[19] N. Nisan and A. Ronen, Algorithmic mechanism design, Games and Economic Behavior 35 (2001), no. 1-2, 166-196.

[20] B. Tan and S. B. Gershwin, Production and subcontracting strategies for manufacturers with limited capacity and volatile demand, Annals of Operations Research 125 (2004), no. 1-4, 205-232.

[21] Y. Vakrat and A. Seidmann, Implications of the bidders' arrival process on the design of online auctions, Proceedings of the 33rd Hawaian International Conference on Systems Sciences, Hawaii, 2000, pp. 1-10.

[22] M. Van Alstyne, The state of network organization: a survey in three frameworks, Journal of Organizational Computing and Electronic Commerce 7 (1997), no. 2\&3, 83-151.

[23] D. Veeramani and K. J. Wang, Performance analysis of auction-based distributed shop-floor control schemes from the perspective of the communication system, International Journal of Flexible Manufacturing Systems 9 (1997), no. 2, 121-143. 


\section{Cooperation of manufacturers on production capacity}

[24] M. P. Wellman, W. E. Walsh, P. R. Wurman, and J. K. MacKie-Mason, Auction protocols for decentralized scheduling, Games and Economic Behavior 35 (2001), no. 1-2, 271-303.

Barış Tan: Graduate School of Business, Koç University, Rumelifeneri Yolu Saryer, 34450 Istanbul, Turkey

E-mail address: btan@ku.edu.tr 


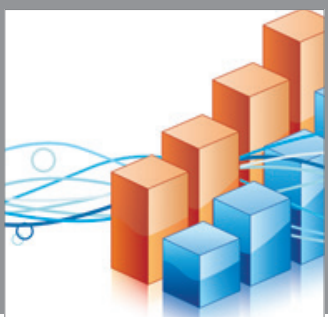

Advances in

Operations Research

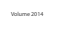

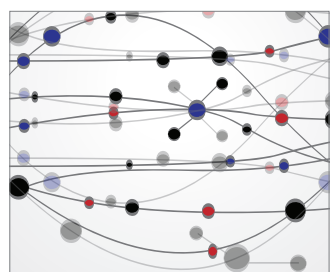

\section{The Scientific} World Journal
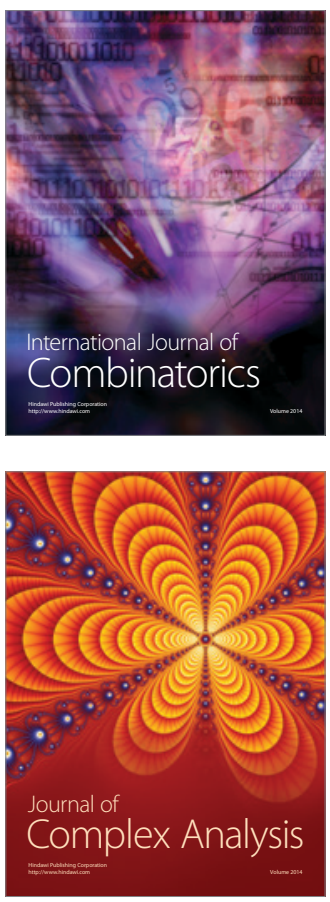

International Journal of

Mathematics and

Mathematical

Sciences
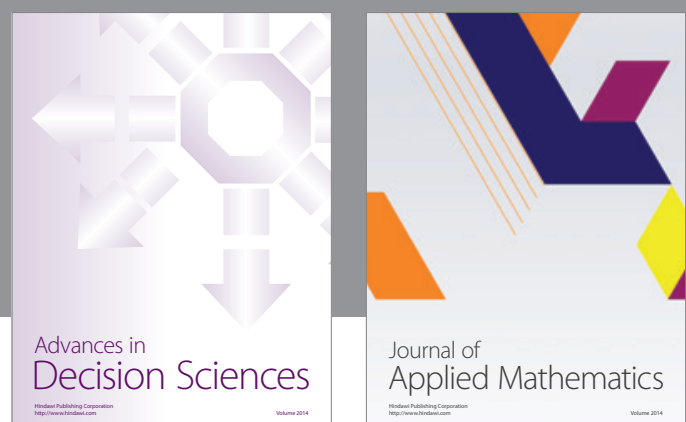

Journal of

Applied Mathematics
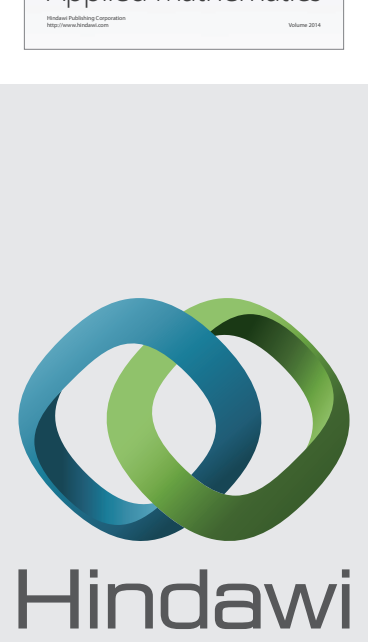

Submit your manuscripts at http://www.hindawi.com
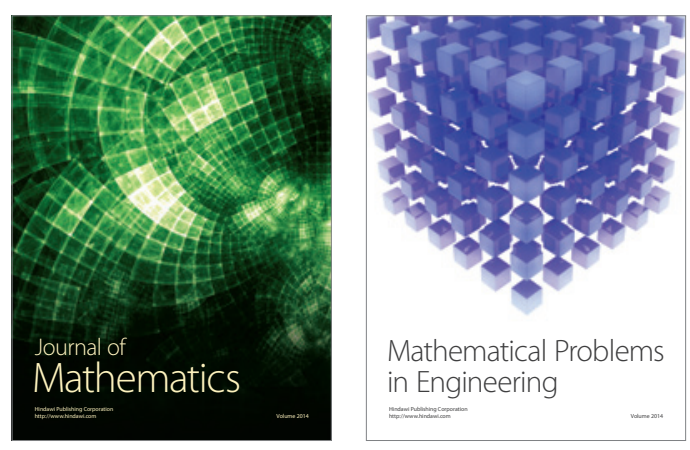

Mathematical Problems in Engineering
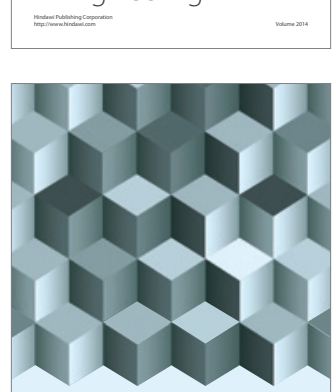

Journal of

Function Spaces
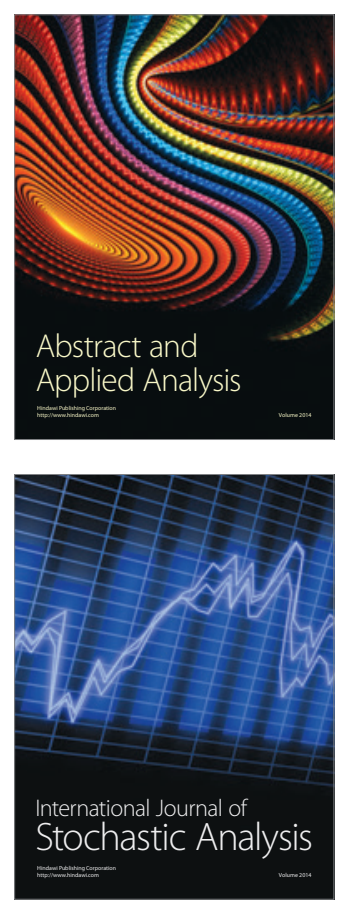

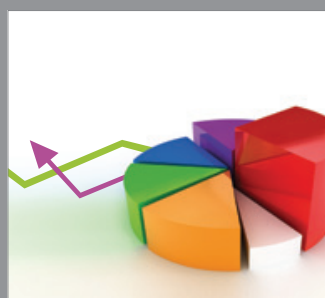

ournal of

Probability and Statistics

Promensencen
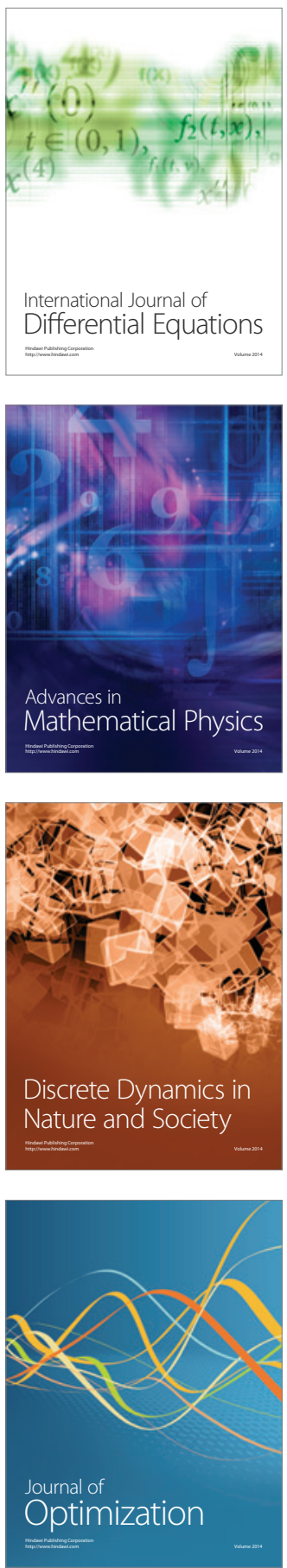